\title{
Masculinidades e rupturas após a penectomia
}

\author{
Masculinities and ruptures after penectomy \\ Masculinidades y rupturas después de la penectomía \\ Vander Monteiro da Conceição ${ }^{1}$ Đnttps://orcid.org/0000-0003-0972-0795 \\ Kassiano Carlos Sinski ${ }^{1}$ @entps://orcid.orgy/0000-0001-9718-9388

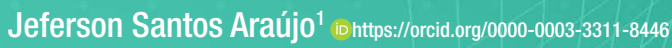 \\ Julia Valeria de Oliveira Vargas Bitencourt ${ }^{1}$ (E)ttps://orcid.org/0000-0002-3806-2288 \\ Lucialba Maria Silva dos Santos ${ }^{2}$ ienttps://orcid.org/0000-0003-4603-4567 \\ Marcia Maria Fontão Zago ${ }^{3}$ ionttps://orcid.org/0000-0001-6539-2584
}

Como citar:

Conceição VM, Sinski KC, Araújo JS, Bitencourt JV, Santos LM, Zago MM. Masculinidades e rupturas após a penectomia. Acta Paul Enferm. 2022;35:eAPE03212.

DOI

http://dx.doi.org/10.37689/acta-ape/2022A003212

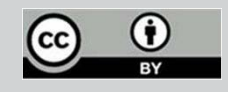

Descritores

Neoplasias penianas; Pênis/cirurgia; Antropologia médica; Masculinidade; Saúde do homem; Enfermagem oncológica

Keywords

Penile neoplasms; Penis/surgery; Anthropology, medical; Masculinity; Men's health; Oncology nursing

\section{Descriptores}

Neoplasias del pene; Pene/cirurgía; Antropología médica Masculinidad; Salud del hombre

Submetido 24 de Outubro de 2020

Aceito

26 de Maio de 202

Autor correspondente

Vander Monteiro da Conceição E-mail: vander.conceicao@uffs.edu.br

Editor Associado (Avaliação pelos pares): Camila Takao Lopes Escola Paulista de Enfermagem, Universidade Federal de São Paulo, São Paulo, SP, Brasil

\section{Resumo}

Objetivo: Analisar os significados das masculinidades durante a vivência do câncer peniano e seus tratamentos.

Métodos: Abordagem qualitativa de pesquisa amparada em referencial teórico da antropologia médica e das masculinidades, com o emprego do método narrativo. Foram entrevistados em profundidade 18 homens com neoplasia peniana em um hospital referência em uro-oncologia do estado de São Paulo. Cada participante foi entrevistado com roteiro de investigação, em média três vezes, sendo as entrevistas audiogravadas, transcritas e analisadas conforme a análise temática indutiva.

Resultados: Seis participantes realizaram a penectomia parcial e 12 total. Em relação ao estado civil, participaram dois viúvos, dois solteiros, três divorciados e 11 casados, com média de idade de 54 anos. A extirpação do pênis promoveu mudanças significativas na forma como os homens performavam suas masculinidades, sobretudo a hegemônica. Portanto, essa experiência Ihes permitiu reinterpretar suas condições de saúde na tentativa de identificar outros elementos hegemônicos que sustentassem suas imagens masculinas. Para alguns foi possível representar um homem inteiro, porém outros se consideram agora meio-homens.

Conclusão: 0 adoecimento rompeu com o fluxo biográfico dos participantes, pois antes do câncer peniano a hegemonia os representava como masculinos, entretanto, após a penectomia, eles perdem um órgão que socialmente traz atributos como força, poder, trabalho e virilidade, situação que Ihes trouxe a necessidade de reinterpretar o ser masculino em suas culturas. A enfermagem, para promover o cuidado integral ao homem, deve considerar que as masculinidades interferem no processo saúde e doença.

\section{Abstract}

Objective: To analyze masculinity meanings during penile cancer experience and its treatments.

Methods: Qualitative approach supported in the theoretical framework of medical anthropology and masculinities, with the use of the narrative method. We interviewed in-depth 18 men with penile cancer in a referential Urologic Oncology hospital from the state of São Paulo. Each participant was interviewed on average three times, with a structured script, being the interviews audio-recorded, transcribed, and analyzed according to the inductive thematic analysis.

Results: Six patients were submitted to the partial penectomy and 12 to the total penectomy. Regarding the marital status, six were widowers, two single, three divorced, and 11 married, with an average age of 54 years old. The penis extirpation fostered significant change in the way men performed their masculinities, even the hegemonic. Thus, this experience allowed them to reinterpret their health conditions to identify other hegemonic elements that sustained their masculine images. For a few, it was possible to represent a full man however, others considered themselves half-men.

Universidade Federal da Fronteira Sul, Chapecó, RS, Brasil.

2Fundação Centro de Hemoterapia e Hematologia do Pará, Belém, PA, Brasil.

3Universidade de São Paulo, Escola de Enfermagem de Ribeirão Preto, Ribeirão Preto, SP, Brasil.

Conflitos de interesse: nada a declarar. 
Conclusion: The illness broke the participant's biographic flow because, before penile cancer, the hegemony represented them as masculines, however, after the penectomy, they have lost an organ that is socially related to attributes such as strength, power, work, and virility, situation that brought them the necessity to reinterpret being masculine in their culture. To promote integrality of care to man the nursing must consider that masculinities interfere in the process of health and disease.

\section{Resumen}

Objetivo: Analizar los significados de las masculinidades durante la vivencia del cáncer de pene y sus tratamientos.

Métodos: Enfoque cualitativo de investigación respaldado en el marco referencial teórico de la antropología médica y de las masculinidades, con el uso del método narrativo. Fueron entrevistados en profundidad 18 hombres con neoplasia de pene en un hospital de referencia en urología oncológica del estado de São Paulo. Cada participante fue entrevistado con guion de investigación, tres veces en promedio. Las entrevistas fueron grabadas, transcriptas y analizadas de acuerdo con el análisis temático inductivo.

Resultados: Seis participantes realizaron penectomía parcial y 12 total. Respecto al estado civil, participaron dos viudos, dos solteros, tres divorciados y 11 casados, con un promedio de edad de 54 años. La extirpación del pene generó cambios significativos en la forma como los hombres practicaban su masculinidad, sobre todo la hegemónica. Por lo tanto, esta experiencia les permitió interpretar sus condiciones de salud en el intento de identificar otros elementos hegemónicos que sostengan su imagen masculina. Para algunos fue posible representar un hombre entero, pero otros ahora se consideran medio hombres.

Conclusión: La enfermedad rompió con el flujo biográfico de los participantes, ya que antes del cáncer de pene, la hegemonía los representaba como masculinos; sin embargo, después de la penectomía, perdieron un órgano que socialmente trae atributos como fuerza, poder, trabajo y virilidad, situación que les produjo la necesidad de reinterpretar el ser masculino en su cultura. Para promover el cuidado integral del hombre, la enfermería debe considerar que las masculinidades interfieren en el proceso salud y enfermedad.

\section{Introdução}

O câncer de pênis representa mundialmente menos de $1 \%$ dos tumores malignos. No panorama epidemiológico de distribuição de casos novos desse câncer, foi identificado que na Índia, em 2008, ele representava $3,32 \%$ do total de neoplasias diagnosticadas; na África, em 2013, mais de 20\%; na América Latina, em 2013, de $10 \%$ a $20 \%$ do total. No Brasil, de acordo com o último dado publicado, em 2013, a incidência de novos casos foi estimada em $0,13 \% .^{(1)}$

A experiência masculina ante o diagnóstico de câncer de pênis remete ao enfrentamento da possível penectomia, total ou parcial. Assim, a relevância do pênis no corpo masculino e do comprimento desse órgão é discutida pela representação da virilidade. Um estudo norte-americano que estabeleceu a relação entre as experiências sexuais masculinas e o autorrelato do comprimento peniano identificou que homens com maior experiência sexual se preocupavam mais com a extensão do pênis, ao contrário dos inexperientes. Tal diferença ocorreu por influência da competência e proeza sexual fomentadas pelo senso de masculinidade. ${ }^{(2)}$

No Reino Unido, em investigação sobre a representação do pênis em revistas para público masculino, identificou-se que homens recebem informaçóes sobre suas masculinidades a partir do mundo social. Houve destaque para a representação da masculinidade a partir do pênis, seja pela medicalização do corpo ou pela discussão de comportamentos masculinos entendidos como negativos para a sociedade, como no caso da violência. ${ }^{(3)}$

Considerando as simbologias masculinas imbricadas socialmente ao pênis, pesquisadores, ao estudarem o adoecimento pelo câncer de próstata, descrevem o sentimento de impotência e a sensação de ausência de controle do corpo, que impedem o desenvolvimento de atividades cotidianas, bem como a resistência à busca dos serviços de saúde. Acredita-se que tal resistência se deva ao exame médico simbolizar a violação da identidade masculina, uma vez que vulnerabiliza o homem. ${ }^{(4)}$ Nesse contexto, o adoecimento e o tratamento do câncer de próstata tendem a assemelhar-se ao que ocorre no caso do câncer de pênis.

Para efetivar a aproximação com o tema "adoecimento pelo câncer de pênis”, foram realizadas buscas na literatura, constando-se que somente um artigo foi produzido nos últimos cinco anos, cujo foco foi o modo como o adoecimento influenciou na experiência pessoal dos participantes. ${ }^{(5)}$ Explicitando-se lacunas acerca da temática câncer de pênis e suas repercussóes na vida dos homens, questiona-se: quais são as vivências masculinas re- 
lacionadas à neoplasia peniana e seus tratamentos? Dessa forma, esta investigaçáo objetivou analisar os significados das masculinidades durante a vivência do câncer peniano e seus tratamentos.

\section{Métodos}

Este estudo é de abordagem qualitativa e tem como referencial teórico a antropologia médica ${ }^{(6)}$ e das masculinidades. ${ }^{(7)}$ Foi empregado o método narrativo para operacionalizar a apresentação dos resultados, conforme os pressupostos do paradigma interpretativo, e estruturado de acordo com os preceitos do Consolidated Criteria for Reporting Qualitative Research. ${ }^{(8)}$

Para a antropologia médica, a cultura reconhece o homem como um ser consciente de seus pensamentos e de suas práticas. Portanto, para entender o adoecimento, é necessário interpretar como os contextos descritos influenciam a subjetividade dos adoecidos e empregam sentido às suas experiências. ${ }^{(6)}$

O emprego das masculinidades nesse contexto auxiliou os pesquisadores a interpretarem como é ser um homem, sobretudo no adoecimento pelo câncer de pênis. Ao mencionar masculinidades, reconhecem um conceito analítico da prática social masculina com padrão hegemônico e outras múltiplas configurações, ${ }^{(7)}$ devendo as masculinidades serem analisadas nos níveis local, regional e global. ${ }^{(9)}$

Este estudo foi realizado no ambulatório de acompanhamento a homens em tratamento de câncer de pênis de um hospital de referência para o tratamento de neoplasias urológicas no interior do estado de Sáo Paulo. Foram estabelecidos como critérios de inclusão: ter o diagnóstico de câncer de pênis, estar em seguimento ambulatorial e ser maior de 18 anos. Foram abordados 28 homens que atenderam aos critérios pré-estabelecidos, entretanto, apenas 18 aceitaram participar da pesquisa. A esses foi apresentado o termo de consentimento livre e esclarecido, sendo a anuência e concordância registrada por suas assinaturas.

Para coleta dos dados, foi empregado um instrumento para captação de informaçóes socioculturais, um diário de campo e um roteiro com as seguin- tes questóes norteadoras: $\mathrm{O}$ que você sabe sobre este tipo de câncer? Por que você teve esta doença? Como é lidar com os tratamentos? Como está a sua vida agora? O que você pensa sobre o futuro? A sua vida como homem mudou? Por quê?

Os participantes foram entrevistados em profundidade em distintos espaços (casa, praça, bar, sorveteria, lavoura e hospital), conforme solicitação deles, respeitando-se a confidencialidade. É válido ressaltar que, mesmo que algumas entrevistas tenham ocorrido em espaços públicos, o pesquisador e o entrevistado mantiveram-se distantes de pessoas que poderiam ouvir o diálogo, havendo pausa da entrevista quando alguém se aproximava. Cada participante foi entrevistado em média três vezes, no período de 20 meses, de junho de 2015 à janeiro de 2017, com mídia digital audiogravada. A coleta de dados foi interrompida quando o corpus de dados produzidos atendeu aos objetivos propostos. Como houve mais de uma entrevista com cada participante, a entrevista seguinte validava os dados produzidos na anterior, visto que o pesquisador refazia questionamentos e arguia o participante para ratificar o dito anteriormente.

A análise e a coleta dos dados ocorreram em paralelo. Cada entrevista foi analisada conforme a análise temática indutiva, ${ }^{(10)}$ a partir da transcrição e familiarização com os dados. Posteriormente, houve a codificação e recodificação dos dados, e elaboração dos temas representativos para o universo de participantes.

Os temas identificados foram fortalecidos a partir de cada encontro com os participantes e os temas finais organizados segundo a estrutura do método narrativo, o qual propóe a construção do texto narrativo a partir de três situaçóes: 1) a vida antes do fenômeno estudado, 2) o enredo da história contada; e 3) a interpretação, que corresponde a compreensão sábia da história narrada. ${ }^{(11)}$

Para a conduçáo da pesquisa, os autores se apropriaram dos referenciais teóricos e metodológicos adotados e foram supervisionados por pesquisadora/autora com expertise em metodologia qualitativa e estudos culturais.

Considerando o envolvimento de seres humanos, o cuidado ético dos pesquisadores e em ob- 
servância à Resoluçóes 466/2012 e 506/2016, do Conselho Nacional de Saúde, a pesquisa foi submetida e aprovada pelo Comitê de Ética em Pesquisa com Seres Humanos da Escola de Enfermagem de Ribeirão Preto da Universidade de São Paulo, sob o Protocolo no 073/2014 e Certificado de Apresentação de Apreciação Ética (CAAE) no 07484812.0.0000.5393. Os participantes são identificados por nomes fictícios, quando citados no texto.

\section{Resultados}

Entre os participantes, seis realizaram a penectomia parcial e doze total. Em relaçáo à cor da pele, quatro se autodeclararam brancos, dez pardos e quatro pretos. Dois eram viúvos, dois solteiros, três divorciados e onze casados. A média de idade foi de 54 anos. Treze tinham filhos e cinco não. Treze tinham o ensino fundamental completo, um o ensino fundamental incompleto, três eram analfabetos, e um o ensino médio completo. Nove eram aposentados, quatro desenvolviam atividades laborais autônomas, e cinco mencionaram não trabalhar, ou seja, não possuíam renda mensal individual, obtendo seu sustento por doaçóes de amigos e familiares. Dentre os que mencionaram trabalhar, a renda mensal individual variou de um a seis salários-mínimos.

$\mathrm{O}$ processo de análise possibilitou sintetizar as experiências no tema representativo denominado de "Liminaridades masculinas: ser homem inteiro ou meio-homem", como apresentando na figura 1, e posteriormente pelas sínteses narrativas.
Liminaridades masculinas: ser homem inteiro ou meio-homem

Os participantes, após a penectomia, buscaram outros atributos para ainda se entenderem como homens em seu grupo social, mesmo reconhecendo que houve mudanças significativas no cotidiano e na forma de expressar suas masculinidades. Em outras palavras, mantiveram a ideia de homem inteiro, apesar de não terem o pênis (em sua totalidade) e os sentidos a ele atribuído.

Antes da doença minha vida social era muito ativa, mas agora reduziu 99,9\%. Minha vida sexual enfraqueceu muito, ainda tenho a vida sexual, pouco, mas tenho! Quando fui experimentar uma relação a primeira vez após a cirurgia, foi normal. Minha esposa leva uma vida normal e tranquila, como se fosse antes ou ainda melhor agora. A importância da relação sexual depende da parceira, é uma coisa difícil de explicar. (Nota de campo: considerando que a maioria dos homens acometidos por câncer de pênis desenvolviam atividades profissionais que exigem força física, a doença os limitou)

Não posso carregar nada, e aqui na minha cidade, emprego de ficar sentadinho não se encontra. Quando preciso de ajuda falo com os meus familiares. (Nota de campo: após simbolizarem acerca do atributo trabatho na vida do homem, falam sobre o lazer)

Meu lazer é sair para uma lanchonete, um barzinho, um churrasco e tomar uma cerveja por diversão. Aos sábados eu gosto de ir ao pesqueiro, passo o dia todo lá com minha esposa. (Nota de campo:

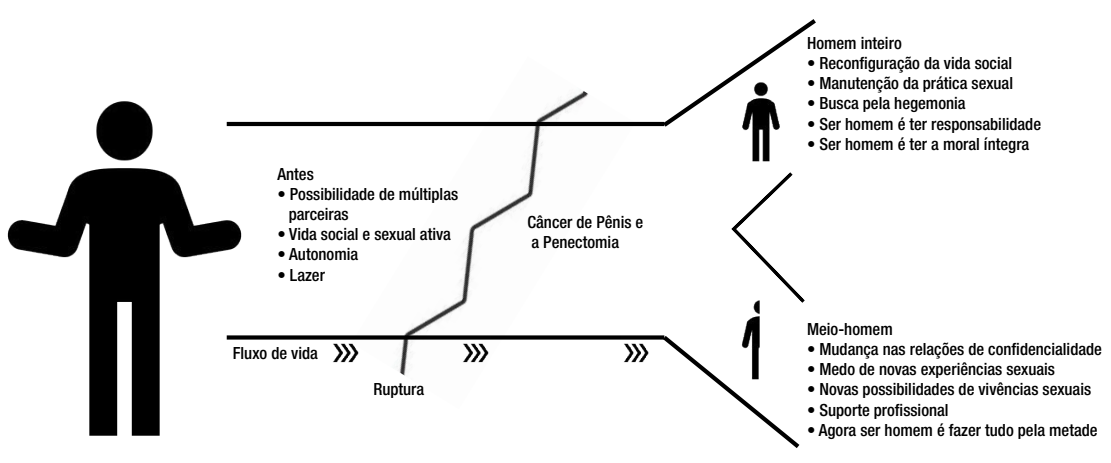

Figura 1. Representação do processo de análise dos dados 
na sequência, passam a simbolizar a ressignificação das masculinidades)

Ser homem para mim é poder fazer tudo. E tem que ter responsabilidade, ser trabalhador, ter o nome limpo, ter caráter, sem processos, cadeia, essas coisas. Não precisa ter pênis para ser homem, tem muita mulher que é muito mais homem. (Heraldo, Bruno, Célio, Alessandro, Italo, Marcelo, Davi, Fabrício, Gabriel e Luiz)

Para outros participantes, a remoção do pênis e as consequências do tratamento promoveram limitaçóes que os conduziram a repensar suas masculinidades, visto que entenderam que suas novas experiências de vida náo sustentam o ser masculino construído e apresentado em seus grupos sociais. Portanto, sentem-se menos homens que os demais. Cunha-se, então, a ideia de meio-homem.

A primeira pessoa para quem contei foi minha mulher. Depois da minha familia, contei para amigos. Vizinho não tem que ficar sabendo da sua intimidade. (Nota de campo: alguns homens revelam ter receio de falar sobre a doença).

Achava que as pessoas poderiam me ignorar, se afastarem por pensarem que esse tipo de enfermidade é contagioso. A pessoa brincalhona pode falar que chegou o homem sem pinto, ou o homem que não é homem. Já falaram que mais um pouco eu virava uma mulher. (Nota de campo: a visibilidade do câncer de pênis é motivo de comparação com o feminino)

O homem quando faz essa cirurgia é visivel. Agora a mulher ao fazer esse tipo de cirurgia (referência ao cancer uterino) se torna invisivel porque a retirada do útero é interna, então ela não sente tanto. (Nota de campo: seguem expressando sobre sua sexualidade no pós-tratamento)

Após a cirurgia, demorei um ano, uns nove, dez meses para manter uma relação sexual. Achava que isso ia acabar dando em separação. (Nota de campo: os homens criaram estratégias de enfrentamento para lidar com sua nova condição)
Não frequento mais locais coletivos que mostram meu corpo como banheiros, piscinas, entre outros. Para abordar minha primeira parceira foi complicado. Trouxe pra casa e tudo, e depois na hora, precisei falar o que era. Fiquei com muita vergonha, mas ela já estava ali e estava gostando, continuou. $A$ região onde havia meu pênis é sensivel, então quando a garota estimula sai um líquido e sinto prazer, mas não é um prazer igual como eu sentia antes. Ainda bato uma punhetinha [masturbação] porque sobrou um toquinho [pequena porção] do meu pênis que ainda endurece. Foi difícil, tive uma ajuda técnica mesmo, foram os psicólogos, os médicos, as enfermeiras que me atenderam que começaram a me dar força sobre isso. (Ailton, Alex, Carlos, Geraldo, Haroldo, Milton, Pedro e Ricardo)

\section{Discussão}

Nas narrativas os participantes expressam suas impressóes sobre esse novo estado de ser, mas as concepçóes acerca do homem que eram antes do câncer de pênis, que entendem como normal, subjazem. $\mathrm{O}$ corpo antes do adoecimento proporcionava prazer, ligava a uma cultura que esse homem tinha como adequada ao seu estereótipo masculino, assim era dominador e exercia o seu poder no trabalho, nas relaçóes sexuais, no papel de provedor da família, na independência financeira e no controle sobre as funçóes do seu corpo.

Em algumas culturas ocidentais o homem é socialmente visto como forte, soberano, viril e não feminino. Nessa perspectiva, existe uma masculinidade hegemônica considerada como padrão, a qual espera a incorporação de um comportamento moral que a sociedade credita ao seu estereótipo masculino. ${ }^{(12)}$ Pesquisadores destacam que a masculinidade é um status que deve ser constantemente demonstrado e validado nas relaçóes culturais, provando o ser masculino com uma reputação valorizada. ${ }^{(13)}$

Com base nas concepçóes das masculinidades hegemônicas, os participantes do estudo simbolizaram em suas narrativas as implicaçóes e os conflitos desencadeados a partir da penectomia, colocando em xeque suas relaçôes sociais, afetivas, de traba- 
lho e lazer. Nessa discussão, sobressai o conceito de normalidade, atrelado à masculinidade hegemônica reconhecida antes do adoecimento como normal, ideal a ser seguido.

Para a cultura, o conceito de normalidade está relacionado com crenças compartilhadas por um grupo. Para haver uma masculinidade hegemônica, deve-se seguir normas simbólicas que a sociedade valoriza nas relaçôes identitárias para um homem. Em busca da manutenção da masculinidade e da volta à normalidade antes imposta, por vezes esses pacientes desenvolvem estratégias para ressignificar seu cotidiano à medida que realizam atividades. ${ }^{(14)}$

Um estudo sobre homens com hemofilia grave descreveu que eles vivenciam estigmas por serem incapazes de viver conforme os ideais de masculinidade, pois sua condição os impede de atingir as expectativas sociais depositadas nos homens. Para minimizar esse impacto, estratégias de gerenciamento podem ser aplicadas para neutralizar o estigma imposto e permitir que eles se distanciem da enfermidade. ${ }^{(15)}$

$\mathrm{O}$ adoecimento tirou os homens do normal e os colocou no patológico, não só do corpo, mas do que é desviante do hegemônico, pois os levou a experiências de passividade, afetividade, dependência, depressão (em alguns casos) e fragilidade. O poder que exerciam sobre si e sobre os outros hoje é um fator moral que os aprisiona por não se sentirem mais livres para expressar sua masculinidade, configurando uma nova identidade: a de meio-homem.

Os homens desta investigação migraram do saudável para o doente e após o tratamento mudaram novamente; agora têm dificuldades de performarem como hegemônicos. Essas mudanças podem causar emoçóes negativas nos homens em decorrência da preocupação com a reputação masculina perante a sociedade e os tornam mais resistentes a mudanças para seguirem o máximo possível suas normas. ${ }^{(16)}$

Alguns participantes deste estudo se reconhecem como meios-homens. São sobreviventes que conseguiram contornar a morte associada às pessoas com câncer, entretanto algumas sequelas. $\mathrm{O}$ câncer retirou a hegemonia masculina, seus corpos e suas açôes não lhes permitem mais se identificarem como homens inteiros. Houve uma ruptura na identidade e adição de novos elementos (isolamento, ausência do pênis, sexualidade com limitaçóes, ausência de trabalho) que o configuram como homens pela metade.

$\mathrm{Na}$ perspectiva antropológica, cada ruptura biográfica corresponde a uma fronteira que se ultrapassa, logo, o fluxo vivenciado se expande com a chegada de novos elementos culturais e sociais que influenciarão o seu cotidiano. ${ }^{(17)}$ Dessa forma, homens que seguem os padróes culturais hegemônicos apresentam um fluxo que identifica sua masculinidade por meio de suas açóes. Porém, com a penectomia, esse fluxo é rompido e transcende uma fronteira social, que irá requerer do homem a apropriação com novos elementos da masculinidade que, minimamente, o mantenham no seu status social masculino.

Doenças cujas trajetórias são longevas, no caso do HIV/aids e do câncer, tendem a promover rupturas biográficas na vida dos adoecidos, e a cada cisão novas experiências são adicionadas ao seu fluxo de vida. Em uma pesquisa realizada com jovens diagnosticados com HIV, foi observado que o momento de ruptura biográfica promoveu três atitudes: a busca por elementos de sua história, o enfrentamento da realidade atual e as perspectivas para o futuro. ${ }^{(18)}$ Cada atitude mencionada ocorreu para que o adoecido pudesse manejar elementos para lidar com a enfermidade.

Para o homem, o pênis representa socialmente um status simbólico de masculinidade e de identidade dominante. Sem esses atributos, é como se declarar um desertor dessa cultura e se colocar em julgamento social. Conforme evidenciado nas narrativas, muitos homens penectomizados buscaram estratégias de enfrentamento, isolando-se ou declarando que são normais ou que conseguem realizar suas práticas sexuais. No entanto, com essa inserção em profundidade, nota-se que esses diálogos são paradoxais, estratégias de defesa para alimentar a hegemonia.

Um estudo desenvolvido na Austrália com indivíduos em reconstrução e recuperação da sua identidade narrativa e de sua saúde mental, explanou que todos os participantes buscaram um autocontrole para a sua enfermidade, que variou de acordo com cada história de vida. Ao ser analisada a situação, 
segundo a teoria complex adaptive system, foi constatado que isso só é possível devido à capacidade adaptativa para construir uma nova identidade narrativa. ${ }^{(19)}$ No contexto investigado, foi destacado o período em que a pessoa vivencia a doença, pois, de acordo com a idade e o diagnóstico, a renegociação com a identidade masculina sofre mudanças. ${ }^{(20)}$

Foi evidenciado entre as narrativas deste estudo que o homem penectomizado busca componentes que legitimam o status de hegemonia, mesmo quando não há elementos que ratifiquem sua identidade masculina, como o pênis e suas representaçóes. Os participantes narraram sentirem-se mais vulneráveis após a penectomia, visto que agora apresentam dificuldade de manter suas relações sociais e sexuais. Quando se aproximam do ambiente social, há o risco de exposição daquilo que consideram confidencial (a penectomia), logo, náo basta que os homens se reconheçam como masculinos, é preciso que a sociedade também o faça.

A experiência dos homens com câncer de pênis foi regida por vários conceitos interpretativos que auxiliaram a sustentar o significado da experiência como agenciamento do normal após a penectomia. Utilizaram estratégia de enfrentamento para lidar com as barreiras morais impostas na sobrevivência. Pode-se afirmar que, no contexto das masculinidades locais desses homens, o pênis é órgão que as simboliza e que regula as experiências masculinas hegemônicas do seu estereótipo. Na sua ausência, só é suportável pelo sentimento de estar no controle da hegemonia novamente. Assim, os homens vivem um contexto com limitaçóes e seu agenciamento os leva ao sustento da experiência de viver como um homem pela metade.

As limitaçóes deste estudo são relacionadas aos contextos das masculinidades identificadas, situação justificada pela abrangência regional do grupo investigado. Entretanto, apesar dos dados apresentarem, majoritariamente, representatividade de masculinidades regionais, há elementos que representam a maneira como homens podem performar suas masculinidades globais, como a busca por atributos que ratifiquem sua hegemonia social.

A enfermagem deve apropriar-se desse conhecimento para compreender que, para homens, o adoecimento é um processo e que o produto dessa experiência é construído a partir de rupturas em suas histórias e, consequentemente, as adaptaçóes a essas novas realidades são dolorosas, pois envolvem o modo como eles se veem masculinos em sociedade. Portanto, manejar as subjetividades masculinas incorporadas ao processo saúde-doença é proporcionar o cuidado integral em enfermagem e saúde.

\section{Conclusão}

Nesta investigação, o objetivo proposto foi atendido, pois identificou-se que a doença interrompeu o fluxo biográfico dos participantes. Na vida prévia ao câncer de pênis, os homens performavam suas masculinidades confiantes de que a hegemonia os representava. Após o adoecimento e a penectomia, eles perderam atributos sociais de poder, como o trabalho, a força física e a virilidade. Na tentativa de recuperarem seus discursos hegemônicos, eles elencaram elementos que os mantêm no status de dominação masculina, comparando-se a homens náo penectomizados.

\section{Agradecimentos}

Esta pesquisa recebeu apoio financeiro da Fundação de Amparo à Pesquisa do Estado de São Paulo (FAPESP) sob o protocolo 2013/14891-4.

\section{Colaborações}

Conceição VM, Sinski KC, Araújo JS, Bitencourt JVOV, Santos LMS e Zago MMF colaboraram com a concepção do estudo, análise e interpretação dos dados, redação do artigo, revisáo crítica relevante do conteúdo intelectual e aprovação da versão final a ser publicada.

\section{Referências}

1. Conceição VM, Ramos Al, Araújo JS, Oliveira RA, Bitencourt JV, Sinski $\mathrm{KC}$, et al. Social determinants of patients with penile neoplasia. Rev Enferm UFPE Online. 2019;13(2):338-45. 
2. King BM, Duncan LM, Clinkenbeard KM, Rutland MB, Ryan KM. Social desirability and young men's self-reports of penis size. J Sex Marital Ther. 2019;45(5):452-5.

3. Owen $\mathrm{C}$, Campbell $\mathrm{C}$. How do men's magazines talk about penises? J Health Psychol. 2017;23(2):1-13.

4. Araújo JS, Nascimento LC, Zago MM. Embodied hegemonies: moral dilemmas in the onset of prostate cancer. Rev Esc Enferm USP. 2019;53:e03494.

5. Gordon H, LoBiondo-Wood G, Malecha A. Penis cancer: the lived experience. Cancer Nurs. 2017;40(2):E30-8.

6. Singer M. Medical anthropology. In: Callan H, editor. The international encyclopedia of anthropology. Hoboken: Wiley; 2018.

7. Messerschmidt JW. The salience of hegemonic masculinity. Men Masc. 2019;22(1)85-91.

8. Tong A, Sainsbury P, Craig J. Consolidated Criteria for Reporting Qualitative Research (COREQ): a 32-item checklist for interviews and focus groups. Int J Qual Health Care. 2007;19(6):349-57.

9. Nascimento M, Connell R. Reflecting on twenty years of masculinities: an interview with Raewyn Connell. Cien Saude Colet. 2017;22(12):397580.

10. Clarke V, Braun V. Thematic analysis. J Posit Psychol. 2017;12(3):29798

11. Missel M, Birkelund R. Ricoeur's narrative philosophy: a source of inspiration in critical hermeneutic health research. Nurs Philos. 2020;21(2):e12254
12. Araújo JS, Zago MM. Masculinities of prostate cancer survivors: a qualitative metasynthesis. Rev Bras Enferm. 2019;72(1):231-40.

13. Gul P, Uskul AK. Men's perceptions and emotional responses to becoming a caregiver father: the role of individual differences in masculine honor ideals and reputation concerns. Front Psychol. 2019;10:1442.

14. Polita NB, Alvarenga WA, Leite AC, Araújo JS, Santos LB, Zago MM, et al. Care provided by the father to the child with cancer under the influence of masculinities: qualitative meta-synthesis. Rev Bras Enferm. 2018;71(1):185-94. Review.

15. Reinicke K, Søgaard IS, Mentzler S. Masculinity challenges for men with severe hemophilia. Am J Mens Health. 2019;13(4):1557988319872626.

16. Araújo JS, Conceição VM, Zago MM. Transitory masculinities in the context of being sick with prostate cancer. Rev Lat Am Enfermagem. 2019;27:e3224.

17. Stang F. La frontera como intersticio: reflexiones en torno a la violencia epistémica de las fronterizaciones. Rev Interdiscip Mobil Hum. 2020;28(59):15-30.

18. Agostini R, Maksud I, Franco T. Essa doença para mim é a mesma coisa que nada: reflexões socioantropológicas sobre o descobrir-se soropositivo. Saude Soc. 2017;26(2):496-509.

19. Kerr DJ, Deane FP, Crowe TP. A complexity perspective on narrative identity reconstruction in mental health recovery. Qual Health Res. 2020;30(4):634-49.

20. Pearce S, Whelan J, Kelly D, Gibson F. Renegotiation of identity in young adults with cancer: a longitudinal narrative study. Int J Nurs Stud. 2020;102:103465. 